\title{
Spatial-Temporal Evolution of the Coupling Coordination Relationship between Urbanization and Atmospheric Environment in the Yangtze River Economic Belt, China
}

\author{
Yuxia Deng \\ Nanchang University \\ Xianglian Wang \\ Nanchang Institute of Technology \\ Ting Huang ( $\nabla$ huangting@ncu.edu.cn ) \\ Nanchang University \\ Ya Liu \\ Nanchang University \\ Lian Zeng \\ Nanchang University \\ Xiangwen Zhang \\ Nanchang University \\ Daishe Wu \\ Nanchang University \\ Shan Huang \\ Nanchang University
}

\section{Research Article}

Keywords: the Yangtze River Economic Belt, urbanization, atmospheric environment, coupling coordination, spatial-temporal evolution

Posted Date: October 4th, 2021

DOl: https://doi.org/10.21203/rs.3.rs-947897/v1

License: (c) (1) This work is licensed under a Creative Commons Attribution 4.0 International License. Read Full License 


\section{Abstract}

Based on the coupling coordination degree model and the exploratory spatial data analysis method, we established the coupling coordination relationship between urbanization and atmospheric environment and explored the spatial-temporal evolution characteristics of the coupling coordination degree of 11 provinces in the Yangtze River Economic Belt (YEB) from 2003 to 2017. The results indicated the following: (1) The level of urbanization increases linearly, and the atmospheric environment level shows a fluctuating upward trend. (2) The types of coordination gradually change from "Seriously uncoordinated development with urbanization lag" to "Superiorly coordinated development with atmospheric environment lag". The spatial distribution of coordination shows the characteristics of "high in the eastern region and low in the central and western region". Regarding temporal evolution, the coupling coordination degree of the region gradually increases, and the spatial differences between provinces gradually narrow. (3) Significant spatial autocorrelation is observed between the coordination of urbanization and atmospheric environment, which weakens over time. The local agglomeration mode shows that the "High-High" cluster areas are in the lower reaches and the "Low-Low" cluster areas are mainly in the middle or upper reaches. This study contributes to promoting the sustainable development of the Yangtze River Economic Belt and provides basic data and research perspectives for further investigation of the relationship between urbanization and atmospheric environment.

\section{Introduction}

Since the second half of the 20th century, urbanization has been rapidly increasing around the world (Gupta, 2002). After the reforms and opening-up of the economy, China's urbanization rate increased from $17.9-63.89 \%$ in 1978-2020 (Lin and Zhu, 2018). According to the theory by Northam, China is currently in a phase of accelerated development urbanization (Northam, 1975). Urbanization in China has resulted in improved socioeconomic levels. However, urbanization inevitably causes negative impacts on the environment, especially the impacts on the atmosphere resulting from the coal industry. Regional climate change and local atmospheric environmental pollution have become very prominent. Haze and acid rain occur frequently in China and have an impact on climate change and human health (Yuan et al., 2010).

Since the environmental Kuznets curve (EKC), a model simulating the relationship between urban economic growth and environmental quality, was initially proposed (Grossman and Krueger, 1995), various empirical studies have established a nonlinear relationship by employing it (Diao et al., 2009; Dogan and Turkekul, 2016; Ulucak and Bilgili, 2018). However, EKC also has some limitations. For example, it assumes the independence of the economic and environmental systems and ignores their interactions. Scholars have applied some new theories and methods to explore the relationship between urbanization and the environment. For instance, an improved entropy model was utilized to evaluate the impact of urbanization on the atmospheric environment (Wang et al., 2012), and a gravity model was used to analyze the spatial correlation of pollutants and $\mathrm{CO}_{2}$ emissions in Henan (Chen et al., 2018). Principal component analysis and regression analysis were applied to study the relationship between the 
kernel density model and spatial econometric analysis method were used to explore the dynamic evolution and spatiotemporal process of regional green competitiveness systems (Cheng et al., 2019), while Zhang et al. explored the dynamics of carbon emissions via spatial-temporal analysis (Zhang et al., 2020). Originating in physics, coupling represents the interactions of two or more systems (Li et al., 2012). In recent years, coupling has been widely used to investigate the nonlinear relationship between urbanization and the ecological environment ( Liao, 1999; Wang et al., 2014; Xing et al., 2019).

The atmospheric environment is an important part of the human living environment and can be regarded as one of the contributing factors suppressing the sustainability of human society. Studies have shown that there are spatial spillover effects between urbanization development and atmospheric environment problems (Han and Yu, 2016; Meng et al., 2017), which means that the development of a city will drive the surrounding cities and the air pollution will also affect neighborhoods. Most current research pays close attention to the change in the coupling relationship of a single city in the time series, while few studies focus on the spatial pattern of the regional area (Ding et al., 2015; Jiang et al., 2019). Hence, it is essential to explore the spatial interaction of urbanization-atmospheric environment systems among different areas from the perspective of a large watershed. This study examined the Yangtze River Economic Belt (YEB), collected official data from 2003 to 2017 and established an index system of urbanization and atmospheric environment. Then, the entropy method was utilized to quantitatively describe the development level of urbanization and atmospheric environment. Furthermore, a coupling coordination degree model was used to explore the relationship between urbanization and atmospheric environment. Finally, exploratory spatial data analysis was introduced to analyze the spatiotemporal evolution process of the coupling coordination degree at regional and provincial scales. This study aims to promote the sustainable development of the YEB; moreover, it provides basic data and research perspectives for further work on urbanization and atmospheric environments in other areas facing similar situations.

\section{Study Area}

The YEB $\left(97^{\circ} 20^{\prime} \sim 123^{\circ} 30^{\prime} \mathrm{E}, 21^{\circ} 30^{\prime} \sim 35^{\circ} 20^{\prime} \mathrm{N}\right)$ is a major national strategic development area of China. Its administrative area is approximately 2.05 million square kilometers, accounting for $21.38 \%$ of the land of China. The YEB consists of three regions: upper, middle and lower reaches, including Sichuan, Yunnan, Guizhou and Chongqing; Hubei, Hunan, Jiangxi and Anhui; Jiangsu, Zhejiang and Shanghai, respectively (Fig. 1). As China's largest and most dense river basin economic zone, the regional GDP is approximately CNY 45.16 trillion, accounting for $46.4 \%$ of the country's total GDP in 2020 . The average urbanization rate was $61.7 \%$ in 2019 , higher than the national average (60.6\%). However, long-term extensive economic development increases atmospheric pollutants, far beyond the environmental carrying capacity, and the deterioration of the atmospheric environment will in turn restrict the development of urbanization in the YEB (Bai et al., 2019).

\section{Materials And Methods}


Taking into account the availability and continuity of research data, combined with the specific circumstances of the provinces of the YEB, we selected 2003-2017 as the research interval. The data were derived from the China Statistical Yearbook, China Urban Statistical Yearbook, China Regional Statistical Yearbook, China Environmental Yearbook and China Environmental Statistics Yearbook from 2002 to 2018, as well as the Government Work Report and Statistical Bulletin of National Economy and Social Development of each province. The interpolation method of adjacent years was adopted to supplement the missing individual data.

The extreme-range method (Formulas (1)-(2)) was used to standardize the original data. Depending on the promoting or inhibiting effect, the indicators were divided into positive and negative indicators:

Positive indicator:

$$
Z_{i j}=\frac{X-X_{\min }}{X_{\max }-X_{\min }}
$$

1

Negative indicator:

$$
Z_{i j}=\frac{X_{\max }-X}{X_{\max }-X_{\min }}
$$

where $X$ and $Z_{i j}$ denote the original value and standardized value of indicator $j$ in year $i$, respectively, and $X_{\max }$ and $X_{\min }$ denote the maximum value and minimum value of indicator $\mathrm{j}$, respectively (Wang et al., 2015).

\subsection{The index system}

This paper selected indicators that can reflect the urbanization and atmospheric environment level according to previous studies (Liu, N. et al., 2018; Liu, W. et al., 2018). The urbanization system was divided into four subsystems: population, economy, space and society, for a total of 14 indicators to characterize the comprehensive situation of urbanization in the YEB. Referring to the pressure-stateresponse (PSR) model, the atmospheric environmental system was divided into three subsystems (Rapport and Friend,1979;Wang et al.,2013): atmospheric environmental pressure, state and response, including 11 indices such as per capita industrial waste gas emissions and total industrial $\mathrm{SO}_{2}$ emissions. The final index system is shown in Table 1.

\subsection{Methods}




\subsubsection{Evaluation of urbanization and atmospheric environment}

Urbanization and atmospheric environment are two independent, complex and interactive dynamic systems. In this paper, the weight value was determined by the entropy method (Zou et al., 2006), and the comprehensive level of urbanization and atmospheric environment were calculated by weighted summation according to the weight and standardized value of each index. Since the range method will produce a value of 0 when the index data are standardized and a logarithm is needed in the calculation of the entropy method, it cannot be directly used. Previous research (Han and Ma, 2013) found that for the extreme value 0 , given a small change of $10^{-5}$ or less, the calculated weight is almost unchanged, so we decided to give the extreme value a small change of $10^{-5}$.

The steps were as follows (Formulas (3)-(7)):

Proportion of the indicator $j$ in year $i$ :

$$
p_{i j}=Z_{i j} / \sum_{i=1}^{m} Z_{i j}
$$

Information entropy of the indicator:

$$
e_{j}=-\frac{1}{\ln (n)} \sum_{i=1}^{n} p_{i j} \times \ln \left(p_{i j}\right)
$$

4

Entropy redundancy:

$$
d_{j}=1-e_{j}
$$

5

Weight of the indicator:

$$
\mathrm{w}_{j}=d_{j} / \sum_{j=1}^{n} d_{j}
$$

6 


$$
S_{i j}=\mathrm{w}_{j} \times Z_{i j}
$$

Comprehensive level in year $i$ :

$$
S_{i}=\sum_{i=1}^{n} S_{i j}
$$

8

where $m$ is the number of years and $n$ is the number of indicators.

\subsubsection{Coupling coordination degree model (CCDM)}

The coupling coordination degree model was established to evaluate the relationship between urbanization and atmospheric environment (Liao et al., 2020; Xu and Hou, 2019):

$$
C=\left\{\frac{U_{x} \times A_{y}}{\left(\frac{U_{x}+A_{y}}{2}\right)^{2}}\right\}^{2}
$$

9

$$
T=\alpha U_{x}+\beta A_{y}
$$

10

$$
D=\sqrt{C \times T}
$$

11

where $C$ is the coupling degree; $U_{x}$ and $A_{y}$ represent the comprehensive index of urbanization and atmospheric environment, respectively; $k$ is the adjustment coefficient, let $k=2 ; T$ is the comprehensive coordination index; $D(D \in[0,1])$ is the coupling coordination degree; and $\alpha$ and $\beta$ are the contribution share of urbanization and atmospheric environment. The interaction and status of urbanization development and atmospheric environmental protection are equal, so $a=\beta=0.5$ (Zhang and Liu, 2017). 
To characterize the coupling and coordinated development relationship and stage of the two subsystems more accurately, the coupling and coordinated development level is divided into 3 categories: 5 grades and 15 types (Dai et al., 2018; Liang et al., 2019; Tang, 2015). The classifications are shown in Table 2.

\subsubsection{Exploratory spatial data analysis}

Exploratory spatial data analysis (EDSA) is a collection of various spatial data processing methods and technologies, with spatial autocorrelation analysis as the main function (Anselin, 1996). Spatial autocorrelation refers to the spatial dependence of a variable with spatial attributes in different geographical locations, including global autocorrelation and local autocorrelation. Moran's I, with statistical superiority, is widely used in spatial autocorrelation analysis (Getis, 2007).

The calculation formula of global Moran's / is as follows (Cliff and Ord,1981):

$$
I_{1}=\frac{n \sum_{i=1}^{n} \sum_{j=1}^{n} w_{i j}\left(x_{i}-x\right)\left(x_{j}-x\right)}{\left(\sum_{i=1}^{n} \sum_{j=1}^{n} w_{i j}\right) \sum_{i=1}^{n}\left(x_{i}-x\right)^{2}}
$$

12

The calculation formula of local Moran's / is as follows (Anselin, 1995):

$$
I_{2}=\frac{n\left(x_{i}-x\right)\left[\sum_{j=1}^{n} w_{i j}\left(x_{j}-x\right)\right]}{\sum_{i=1}^{n}\left(x_{i}-x\right)^{2}}
$$

13

where $I_{1}$ is global Moran's $l_{i} I_{2}$ is local Moran's $l ; n$ is the total number of spatial units; $x_{i}$ and $x_{j}$ are the attribute values of space units $i$ and $j$, respectively; $x$ is the mean value of all space unit property values; and $w_{i j}$ is the weight. The range of Moran's / index is $[-1,1] . / \in[-1,0)$ represents negative spatial autocorrelation, $I \in(0,1)$ represents positive autocorrelation, and $I=0$ represents no correlation. After calculating /index, it is generally necessary to test the results statistically: $Z_{I}=\frac{I-E(I)}{S(I)}$, where $S(I)=\sqrt{\operatorname{Var}(I)}$.

\section{Table 1}

Index system of urbanization and atmospheric environment and the entropy weights. 


\begin{tabular}{|c|c|c|c|c|}
\hline System & Subsystem & $\begin{array}{l}\text { Subsystem } \\
\text { weight }\end{array}$ & Index & $\begin{array}{l}\text { Entropy } \\
\text { weight }\end{array}$ \\
\hline \multirow[t]{14}{*}{ Urbanization } & \multirow{3}{*}{$\begin{array}{l}\mathrm{X}_{1} \\
\text { Population } \\
\text { aspects }\end{array}$} & \multirow[t]{3}{*}{0.171} & $\mathrm{X}_{11}$ Nonagricultural population rates (\%) & 0.059 \\
\hline & & & $\begin{array}{l}\mathrm{X}_{12} \text { Urban population density } \\
\text { (people } / \mathrm{km}^{2} \text { ) }\end{array}$ & 0.056 \\
\hline & & & $\begin{array}{l}\mathrm{X}_{13} \text { Percentage of employment in the } \\
\text { secondary and tertiary industry (\%) }\end{array}$ & 0.055 \\
\hline & \multirow{3}{*}{$\begin{array}{l}\mathrm{X}_{2} \text { Economic } \\
\text { aspects }\end{array}$} & \multirow[t]{3}{*}{0.213} & $\mathrm{X}_{21}$ Per capita GDP (Yuan) & 0.085 \\
\hline & & & $\begin{array}{l}X_{22} \text { Proportion of the value of secondary } \\
\text { and tertiary industry to GDP (\%) }\end{array}$ & 0.058 \\
\hline & & & $\begin{array}{l}X_{23} \text { Per capita gross industrial output } \\
\text { above scale }(10,000 \text { Yuan })\end{array}$ & 0.070 \\
\hline & \multirow{4}{*}{$\begin{array}{l}X_{3} \text { Spatial } \\
\text { aspects }\end{array}$} & \multirow[t]{4}{*}{0.250} & $\mathrm{X}_{31}$ Built-up areas $\left(\mathrm{km}^{2}\right)$ & 0.079 \\
\hline & & & $\begin{array}{l}X_{32} \text { Per capita urban residents living } \\
\text { space }\left(\mathrm{m}^{2}\right)\end{array}$ & 0.060 \\
\hline & & & $\mathrm{X}_{33}$ Per capita urban road areas $\left(\mathrm{m}^{2}\right)$ & 0.053 \\
\hline & & & $\begin{array}{l}X_{34} \text { Per capita urban public green area } \\
\left(\mathrm{m}^{2}\right)\end{array}$ & 0.057 \\
\hline & \multirow[t]{4}{*}{$\begin{array}{l}\mathrm{X}_{4} \text { Social } \\
\text { aspects }\end{array}$} & \multirow[t]{4}{*}{0.366} & $\begin{array}{l}X_{41} \text { Per capita total retail sales of social } \\
\text { consumer goods }(10,000 \text { Yuan })\end{array}$ & 0.100 \\
\hline & & & $X_{42}$ Number of doctors per 10,000 people & 0.139 \\
\hline & & & $\begin{array}{l}X_{43} \text { Number of college students per } \\
10,000 \text { people }\end{array}$ & 0.044 \\
\hline & & & $\begin{array}{l}X_{44} \text { Total number of public transportation } \\
\text { vehicles }\end{array}$ & 0.083 \\
\hline \multirow[t]{4}{*}{$\begin{array}{l}\text { Atmospheric } \\
\text { Environment }\end{array}$} & \multirow[t]{4}{*}{$Y_{1}$ Pressure } & \multirow[t]{4}{*}{0.514} & $\begin{array}{l}Y_{11} \text { Total industrial exhaust emissions } \\
\text { per capita }\left(10,000 \mathrm{~m}^{3} / \text { people }\right)\end{array}$ & 0.208 \\
\hline & & & $\begin{array}{l}Y_{12} \text { Number of car ownership per } 10,000 \\
\text { people }\end{array}$ & 0.074 \\
\hline & & & $\mathrm{Y}_{13}$ Industrial $\mathrm{SO}_{2}$ emissions $(10,000 \mathrm{t})$ & 0.140 \\
\hline & & & $\begin{array}{l}Y_{14} \text { Industrial soot and dust emissions } \\
\text { tdata.js } 0 \text { t) }\end{array}$ & 0.091 \\
\hline
\end{tabular}




\begin{tabular}{|c|c|c|c|}
\hline \multirow[t]{4}{*}{$Y_{2}$ State } & \multirow[t]{4}{*}{0.311} & 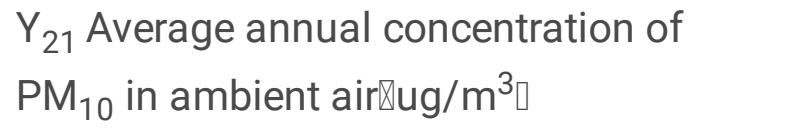 & 0.062 \\
\hline & & $\begin{array}{l}\mathrm{Y}_{22} \text { Average annual concentration of } \mathrm{SO}_{2} \\
\text { in ambient airØug } / \mathrm{m}^{3} \square\end{array}$ & 0.107 \\
\hline & & $\begin{array}{l}\mathrm{Y}_{23} \text { Average annual concentration of } \mathrm{NO}_{2} \\
\text { in ambient air }\left(\mathrm{ug} / \mathrm{m}^{3}\right)\end{array}$ & 0.052 \\
\hline & & $\begin{array}{l}Y_{24} \text { Qualified rate of ambient air quality } \\
(\%)\end{array}$ & 0.090 \\
\hline \multirow{3}{*}{$\begin{array}{l}Y_{3} \\
\text { Response }\end{array}$} & \multirow[t]{3}{*}{0.175} & $\mathrm{Y}_{32}$ Ratio of $\mathrm{SO}_{2}$ removed (\%) & 0.067 \\
\hline & & $\begin{array}{l}Y_{33} \text { Ratio of industrial soot and dust } \\
\text { removed(\%) }\end{array}$ & 0.062 \\
\hline & & $\begin{array}{l}Y_{34} \text { Greening ratio within constructed } \\
\text { areas (\%) }\end{array}$ & 0.056 \\
\hline
\end{tabular}

Table 2 Classification of coupling coordinated development types of urbanization and atmospheric environment. 


\section{Primary}

Catalog
Secondary Catalog

$\begin{array}{lll}\text { Uncoordinated } & 0< & \text { Seriously } \\ \text { development } & \mathrm{D} & \text { uncoordinated } \\ & \leq & \\ & 0.2 & \text { development }\end{array}$

$\begin{array}{ll}0.2 & \text { Moderately } \\ <\mathrm{D} & \\ \leq & \text { uncoordinated } \\ 0.4 & \text { development }\end{array}$

Tertiary Catalog

Type

Serious incoordination with lagging urbanization

urbanization and atmospheric environment

$$
U_{x}-A_{y}>0.1
$$

Serious incoordination

with lagging atmospheric environment

$$
\begin{aligned}
& A_{y}-U_{x}>0.1 \\
& 0 \leq \mid U_{x}-A_{y} \\
& \mid \leq 0.1 \\
& U_{x}-A_{y}>0.1
\end{aligned}
$$

Moderate incoordination with lagging urbanization Moderate incoordination

of urbanization and atmospheric environment

Moderate incoordination with lagging atmospheric environment

$\begin{array}{lll}\begin{array}{lll}\text { Transitional } \\ \text { development }\end{array} & \begin{array}{l}0.4 \\ <\mathrm{D}\end{array} & \text { Barely } \\ & \leq & \text { coordinated } \\ & 0.6 & \text { development }\end{array}$

$$
A_{y}-U_{x}>0.1
$$

Little coordination with III-1 lagging urbanization

$$
\begin{aligned}
& 0 \leq \mid U_{x}-A_{y} \\
& \mid \leq 0.1
\end{aligned}
$$

Little coordination of urbanization and atmospheric environment

$$
U_{x}-A_{y}>0.1
$$

Little coordination with

lagging atmospheric environment

$$
\begin{array}{ll}
0.6 & \text { Moderately } \\
<\mathrm{D} & \text { coordinated } \\
\leq & \text { development } \\
0.8 &
\end{array}
$$

$$
A_{y}-U_{x}>0.1 \quad \begin{aligned}
& \text { Moderate coordination } \\
& \text { with lagging urbanization }
\end{aligned}
$$

$0 \leq \mid U_{x}-A_{y}$ Moderate coordination of

$$
\mid \leq 0.1
$$
urbanization and atmospheric environment

$$
U_{x}-A_{y}>0.1
$$

Moderate coordination

with lagging atmospheric environment

$\begin{array}{lll}\text { Coordinated } & 0.8 & \text { Superiorly } \\ \text { development } & <\mathrm{D} & \text { coordinated } \\ & \leq 1 & \text { development }\end{array}$

$$
A_{y}-U_{x}>0.1 \quad \begin{aligned}
& \text { Advanced coordination } \\
& \text { with lagging urbanization }
\end{aligned}
$$

$$
\begin{aligned}
& 0 \leq \mid U_{x}-A_{y} \\
& \mid \leq 0.1
\end{aligned}
$$

Advanced coordination of urbanization and atmospheric environment

$$
U_{x}-A_{y}>0.1
$$

Advanced coordination 


\section{Results}

\subsection{Analysis of the urbanization and atmospheric environment comprehensive levels}

\subsubsection{Main impact indicators}

As shown in Table 1. For the urbanization subsystem, the weights of population, economic, spatial and social index are $17.1 \%, 21.3 \%, 25.0 \%$ and $36.7 \%$, respectively. The main specific indicators are the number of doctors per 10,000 people (13.9\%), per capita total retail sales of social consumer goods $(10.0 \%)$, per capita GDP (8.5\%) and built-up areas (7.9\%). The results show that from 2003 to 2017 , social urbanization plays a dominant role in the urbanization process of the YEB. The population's consumption level and medical level become the main factors affecting social development after urbanization. Moreover, economic growth remains one of the noteworthy features of urbanization.

In the atmospheric environment subsystem, the weights of pressure, state and response are $51.4 \%, 31.1 \%$ and $17.5 \%$, respectively. The indicators that have the greatest impact on the environment are the total industrial exhaust emissions per capita (20.8\%), industrial $\mathrm{SO}_{2}$ emissions $(14.0 \%)$ and the average annual concentration of $\mathrm{SO}_{2}$ in ambient air (10.7\%). The results show that the pressure subsystem is the most essential factor influencing the evolution of the atmospheric environment. The emission of industrial waste gas, especially the emission of industrial $\mathrm{SO}_{2}$, has caused significant damage to the air quality in the YEB.

\subsubsection{Change trends of the level of urbanization and atmospheric environment}

Figure 2 shows that the comprehensive level of urbanization shows a linear upward trend from 2003 to $2017\left(y=-142.3+0.071 x, R^{2}=0.998\right)$, and the index value increases from 0.0035 to 0.9976 with an average annual growth rate of $49.81 \%$. In terms of subsystems, population, economic, spatial and social urbanization levels all maintain a growth trend. Before 2011, the contributions of these four subsystems to the comprehensive level show little difference. While the level of social urbanization has significantly increased since 2012, the other three subsystems have maintained relatively flat growth patterns of spatial > economy > population. Social urbanization is the primary factor to improve the comprehensive level of urbanization. The growth of population during urbanization has gradually slowed down and has been lower than the development of other subsystems since 2011, becoming the most inhibitory factor in urbanization development.

As shown in Fig. 3, the comprehensive level of the atmospheric environment shows a fluctuating upward trend from 2003 to 2017 . The index value increases from 0.4312 to 0.6049 with an average annual growth of $2.45 \%$. In terms of subsystems, the score of atmospheric environmental pressure shows a 
emissions of pollutants such as industrial $\mathrm{SO}_{2}$ and smoke (powder) dust to increase sharply, and the atmospheric environmental pressure increased accordingly. In September 2013, the State Council issued the "Notice of the State Council on the Issuance of the Action Plan Air Pollution Control", which formulated 10 measures for air pollution prevention, including reducing pollutant emissions, promoting cleaner production, and adjusting the energy structure. The score of atmospheric environmental pressure

gradually increases under the guidance of policies. Overall, the level of the atmospheric environment state shows an upward trend, but it decreases significantly in 2013. This is due to the introduction of new environmental air quality standards in 2012. The new standard is more stringent, and the air quality evaluation factor has been added. Influenced by the policy change, the level of the atmospheric environment state has decreased sharply. The level of atmospheric environmental response essentially remains unchanged from 2003 to 2014 and has shown an upward trend since 2014, indicating that the provinces in the YEB keep pace with the national advocacy of environmental protection and have improved their ability to control atmospheric pollution.

\subsection{Spatiotemporal pattern of coupling coordination degree 4.2.1 Temporal evolution tendency}

As shown in Fig. 4, the coupling coordination degree shows a fluctuating upward trend from 2003-2017, and the index value increases from 0.0148 to 0.8414 with an average annual growth of $33.45 \%$. The coupling coordination degree experiences a total of 7 types from 2003 to 2017, and 2011-2012 is a transitional stage (IV-2). Before this stage, the coupling coordination degree of the YEB is urbanization lag type (I-1,II-1,III-1,IV-1), and after this stage, it becomes atmospheric environment lag type (IV-3,V-3).

Combined with the variation tendency and the evolution process of type, we divided the coupling coordination process of urbanization and atmospheric environment into four stages:

(1) 2003-2006: The coupling coordination degree presents a linear growth trend $\left(y=0.1624 x-325.34, R^{2}\right.$ $=0.9959$ ), and the coupling coordination type changes from "Seriously uncoordinated development with lagging urbanization" to "Barely coordinated development with lagging urbanization". During this period, the growth rate of the urbanization level index is greater than that of the atmospheric environment, but its value is smaller. Urbanization development in the YEB is in its infancy, which causes some interference with the atmospheric environment, though it is not serious.

(2) 2006-2012: The coupling coordination degree maintains a linear growth trend $(y=0.0393 x-78.399$, $\left.\mathrm{R}^{2}=0.9633\right)$, and the growth rate slows down significantly compared to the previous stage. The type changes from "'Barely coordinated development with lagging urbanization" to "Moderately coordinated development of urbanization and atmospheric environment". The value of the urbanization level grows at a high speed, and the value of the atmospheric environment level initially increases, then decreases and subsequently increases. In 2011, the level of urbanization exceeds the level of the atmospheric environment, indicating that the main factor affecting the degree of coupling coordination will gradually

Loading [MathJax]/jax/output/CommonHTML/fonts/TeX/fontdata.js vironment level.

Page $12 / 29$ 
(3) 2012-2014: The coupling coordination degree tends to decrease, and the type changes from "Moderately coordinated development of urbanization and atmospheric environment" to "Moderately coordinated development with lagging atmospheric environment". During this period, the level of urbanization maintains stable growth, and the level of the atmospheric environment shows a similar downward trend to the coupling coordination degree. This phenomenon likely occurs because the pressure of urbanization on the atmospheric environment exceeds the environmental carrying capacity in the YEB.

(4) 2014-2017:The coupling coordination degree tends to increase, and the type changes from "Moderately coordinated development with lagging atmospheric environment" to "Superiorly coordinated development with lagging atmospheric environment". The level of urbanization and atmospheric environment are both on the rise, and the growth curve of the atmospheric environment is nearly parallel with the coupling coordination degree.During this period, the urbanization level of the YEB reaches a favorable stage, and the level of atmospheric environment is the limiting factor affecting the development of coupling coordination degree.

\subsubsection{Spatial distribution characteristics}

We divided the coordination degree into five classes based on its value and selected 2003, 2006, 2009, 2012, 2014 and 2017 as representative years. As shown in Fig. 5, in 20037 provinces (i.e., Sichuan, Yunnan, Chongqing, Guizhou, Hunan, Anhui, and Jiangxi) are in an uncoordinated state, and Yunnan and Guizhou provinces belong to a "Seriously uncoordinated development" type. 3 provinces (i.e., Hubei, Jiangsu, and Zhejiang) are in barely coordinated state, and only Shanghai is moderately coordinated. In 2006, 3 provinces (i.e., Yunnan, Guizhou, and Anhui) are moderately uncoordinated, 5 provinces (i.e., Sichuan, Chongqing, Hubei, Hunan, and Jiangxi) are in barely coordinated state and 3 provinces (i.e., Jiangsu, Shanghai, and Zhejiang) reach a state of moderate coordination. In 2009, only Guizhou Province is in an uncoordinated state, 7 provinces (i.e., Sichuan, Yunnan, Chongqing, Hunan, Hubei, Anhui, and Jiangxi) are in barely coordinated state, and the provinces with moderate coordination remain unchanged. In 2012 and 2014, Yunnan and Guizhou provinces are in barely coordinated state, and the other provinces are all in a state of moderate coordination. In 2017, Guizhou Province is in a barely coordinated state, Shanghai and Zhejiang provinces are superiorly coordinated, and the rest of the provinces are in a state of moderate coordination.

A radar map was drawn to reflect the spatiotemporal evolution of the coupling coordination degree in the YEB more intuitively from a global view (Fig. 6). Comparing the radar curves in 2003 and 2017, the closed curve in 2003 is an irregular polygon, indicating that the coupling coordination level of 11 provinces in the YEB is quite different and unevenly distributed in space. The relatively neat closed curve in 2017 indicates that the development level of the coupling coordination degree of provinces gradually becomes closer, illustrating a relatively uniform state in space.

Bases on previous analysis, the coupling coordination degree of urbanization and the atmospheric 
differences. Provinces in the eastern region, such as Shanghai and Zhejiang, have superior geographical locations and good economic foundations. During rapid urbanization, they also pay attention to energy conservation and atmospheric environmental governance. In contrast, the economic development and infrastructure construction of most provinces in the central and western regions lag. Impractical industrial structure, waste of resources and discharge of pollutants result in poor coordinated development between urbanization and atmospheric environment. With time, the eastern regions have a radiation-driving effect on the central and western regions in space, and the development of the YEB has been changing to a more coordinated state.

\subsection{The spatial agglomeration characteristics of the coupling coordination degree}

\subsubsection{Global autocorrelation analysis}

Table 3 shows that the global Moran's / values are all positive and pass the significance test $(Z(I)>2.58$, $P(I)<0.01)$ from 2003 to 2017, implying that the coupling coordination degree of the YEB presents a significant spatial positive autocorrelation. The coupling coordination degree between adjacent provinces in the region is interrelated and interdependent, showing a spatial aggregation pattern. The provinces with a high degree of coupling coordination show a spatial trend of adjacent aggregation, and vice versa. The global Moran's / present a fluctuating downward trend, showing that the spatial agglomeration of the coupling coordination degree in the YEB is weakening and the gap between provinces is gradually narrowing.

Table 3 Global Moran's / value in 2003-2017. 


\begin{tabular}{|cllr|}
\hline Year & Moran's I & $S(I)$ & $Z(I)$ \\
\hline 2003 & 0.5318 & 0.1885 & 3.3622 \\
\hline 2004 & 0.5454 & 0.1922 & 3.3669 \\
\hline 2005 & 0.5602 & 0.1934 & 3.4281 \\
\hline 2006 & 0.5509 & 0.1943 & 3.3664 \\
\hline 2007 & 0.5498 & 0.1945 & 3.3615 \\
\hline 2008 & 0.5573 & 0.1949 & 3.3728 \\
\hline 2009 & 0.5577 & 0.1944 & 3.4029 \\
\hline 2010 & 0.5745 & 0.1949 & 3.4774 \\
\hline 2011 & 0.5227 & 0.1905 & 3.2888 \\
\hline 2012 & 0.5584 & 0.1968 & 3.3563 \\
\hline 2013 & 0.4662 & 0.1926 & 2.9433 \\
\hline 2014 & 0.3815 & 0.1870 & 2.5837 \\
\hline 2015 & 0.4793 & 0.1975 & 2.9634 \\
\hline 2016 & 0.5049 & 0.1972 & 3.0708 \\
\hline 2017 & 0.4465 & 0.1947 & 2.8100 \\
\hline
\end{tabular}

\subsubsection{Local autocorrelation analysis}

(1) The Moran scatter plots of the coupling coordination degree between urbanization and atmospheric environment in the representative years $(2003,2006,2009,2012,2014$, and 2017) are obtained by GeoDa software. The four quadrants of the Moran scatter plot correspond to the following four zones: High-High $(\mathrm{H}-\mathrm{H})$, Low-High (L-H), Low-Low (L-L), and High-Low (H-L). As shown in Fig. 7 and Table 4, in 20033 provinces (i.e., Zhejiang, Jiangsu, and Shanghai) are located in the $\mathrm{H}-\mathrm{H}$ zone. The coordination degrees of these provinces are high, and the values of surrounding areas are similar, indicating an obvious spatial autocorrelation. In addition, 2 provinces (i.e., Jiangxi and Anhui) are located in the L-H zone, which are heterogeneous with the neighborhoods. Furthermore, 5 provinces (i.e., Hunan, Chongqing, Sichuan, Hunan, and Guizhou) are located in the L-L zone. Moreover, Hubei is located in the H-L zone, whose coupling coordination level is higher than that of the adjacent areas. The spatial distribution of the Moran scatter plots in 2006, 2009 and 2012 is the same as that in 2003. In 2014, the provinces included in the H$\mathrm{H}$ and $\mathrm{L}-\mathrm{H}$ zones remain constant. Chongqing and Sichuan provinces that are included in the L-L zone transfer into the $\mathrm{H}-\mathrm{L}$ zone. In 2017, the provinces in the $\mathrm{H}-\mathrm{H}$ and $\mathrm{L}-\mathrm{H}$ zones are still unchanged. Sichuan Province returns to the $\mathrm{L}-\mathrm{L}$ zone from the $\mathrm{H}-\mathrm{L}$ zone. 
During the investigated period, most provinces are included in the $\mathrm{H}-\mathrm{H}$ and $\mathrm{L}-\mathrm{L}$ zones, indicating that the spatially positive autocorrelation of the coupling coordination degree in the YEB is remarkable. Comparing the results over representative years, most provinces do not make a quadrant transition, presenting a certain spatial stability.

(2) The LISA diagram represents the spatial connection mode of the coupling coordination degree between adjacent regions in geographical space and can further test the significance level of spatial agglomeration. As shown in Fig. 8, the agglomeration mode of the provinces of the YEB in the representative years has the following characteristics: In 2003, the "High-High" cluster mode includes 3 provinces (i.e., Jiangsu, Shanghai, and Zhejiang), and Yunnan Province is in the "Low-Low" cluster mode. The rest of the provinces in the YEB do not have significant spatial agglomeration characteristics. In 2006, the provinces in the "High-High" and "Low-Low" cluster modes remain unchanged, and Anhui Province transforms into the "Low-High" outlier mode. The LISA diagram of the spatial agglomeration mode in 2009 is the same as that in 2006. In 2012, the "High-High" cluster and "Low-High" outlier modes remain constant. The provinces of the "Low-Low" cluster mode are increased to 2, with Guizhou Province being added. In 2014, Jiangsu and Shanghai provinces are included in the "High-High" cluster, Anhui Province is included in the "Low-High" outlier mode, and Sichuan Province transforms from the "LowLow" cluster mode to the "High-Low outlier mode. In 2017, there are only two agglomeration modes on the diagram: "High-High" cluster mode with Jiangsu and Shanghai provinces and "Low-High" outlier mode with Anhui Province.

Based on the above analysis, the "High-High" cluster appears in the provinces of the lower regions, showing the characteristics of a high coupling coordination degree and a significant spatial aggregation effect. These provinces have a good social and economic foundation in promoting urbanization and atmospheric environment governance. "Low-Low" cluster provinces are mainly in the middle and upper regions of the YEB. Lagging urbanization development and inadequate atmospheric environmental protection affected by geographical location and economic structure results in a state of low coupling coordination. The existence of "High-High" and "Low-Low" cluster provinces reflects the spatial dependence of the coupling coordination degree between urbanization and atmospheric environment. In various years, some provinces showing "Low-High" and "High-Low" outlier modes reflect the spatial heterogeneity of the coordination between urbanization and atmospheric environment. With the evolution of time, fewer provinces show significant agglomeration, and the "Low-Low" cluster areas and "High-Low" outlier areas gradually disappear. This phenomenon shows that the overall coupling coordination degree of the YEB is on the rise, and the differences and imbalance between regions are reducing.

Table 4 Provincial distribution of Moran scatter plot. 


\begin{tabular}{|c|c|c|c|c|}
\hline Year & $\begin{array}{l}\text { The first quadrant } \\
(\mathrm{H}-\mathrm{H})\end{array}$ & $\begin{array}{l}\text { The second } \\
\text { quadrant (L-H) }\end{array}$ & The third quadrant $(L-L)$ & $\begin{array}{l}\text { The fourth } \\
\text { quadrant }(\mathrm{H}-\mathrm{L})\end{array}$ \\
\hline 2003 & $\begin{array}{l}\text { Zhejiang } \\
\text { Jiangsu口 } \\
\text { Shanghai }\end{array}$ & Jiangxi $\square$ Anhui & $\begin{array}{l}\text { Hunan } \square \text { Chongqing } \square \text { Sichuan } \square \\
\text { Yunnan } \square \text { Guizhou }\end{array}$ & Hubei \\
\hline 2006 & $\begin{array}{l}\text { Zhejiang } \\
\text { Jiangsu口 } \\
\text { Shanghai }\end{array}$ & Jiangxi $\square$ Anhui & $\begin{array}{l}\text { Hunan } \square \text { Chongqing } \square \text { Sichuan } \square \\
\text { Yunnan } \square \text { Guizhou }\end{array}$ & Hubei \\
\hline 2009 & $\begin{array}{l}\text { Zhejiang } \\
\text { Jiangsu口 } \\
\text { Shanghai }\end{array}$ & Jiangxi $\square$ Anhui & $\begin{array}{l}\text { Hunan } \square \text { Chongqing } \square \text { Sichuan } \square \\
\text { Yunnan } \square \text { Guizhou }\end{array}$ & Hubei \\
\hline 2012 & $\begin{array}{l}\text { Zhejiang] } \\
\text { Jiangsu[ } \\
\text { Shanghai }\end{array}$ & Jiangxi $\square$ Anhui & $\begin{array}{l}\text { Hunan } \square \text { Chongqing } \square \text { Sichuan } \square \\
\text { Yunnan } \square \text { Guizhou }\end{array}$ & Hubei \\
\hline 2014 & $\begin{array}{l}\text { Zhejiang } \\
\text { Jiangsu[ } \\
\text { Shanghai }\end{array}$ & Jiangxi $\square$ Anhui & $\begin{array}{l}\text { Hunan } \square \text { Yunnan } \square \\
\text { Guizhou }\end{array}$ & $\begin{array}{l}\text { Chongqing } \\
\text { HubeiđSichuan }\end{array}$ \\
\hline 2017 & $\begin{array}{l}\text { Zhejiangl } \\
\text { Jiangsu[ } \\
\text { Shanghai }\end{array}$ & Jiangxi $\square$ Anhui & $\begin{array}{l}\text { Hunan } \square \text { Sichuan } \square \text { Guizhou } \square \\
\text { Yunnan }\end{array}$ & $\begin{array}{l}\text { Chongqing } \\
\text { Hubei }\end{array}$ \\
\hline
\end{tabular}

\section{Discussion And Conclusions}

From 2003-2017, the comprehensive level of urbanization in the YEB maintains a linear upward trend, with the social urbanization subsystem as the primary driving factor. The comprehensive level of the atmospheric environment shows a fluctuating upward trend, and the atmospheric environmental pressure subsystem plays a prominent role in the evaluation of the atmospheric environment.

From a temporal perspective, the coupling coordination degree shows a fluctuating upward trend from 2003 to 2017, with index value increases from 0.0148 to 0.8414 with an average annual growth of $33.45 \%$. The coupling coordination type experiences five stages from "Seriously uncoordinated development" to "Highly coordinated development". From a spatial pattern perspective, the coupling coordination degree of urbanization and atmospheric environment is lower in the central and western regions compared to the eastern region, presenting unbalanced development in space. Moreover, the eastern regions have a radiation-driving effect on the central and western regions spatially.

The global Moran's / value ranges from 0.3815-0.5745 in 2003-2017, indicating that the coupling coordination degree of the YEB presents a significant spatial positive autocorrelation. In the Moran scatter plots, most provinces are located in the $\mathrm{H}-\mathrm{H}$ and L-L zones. This implies that provinces with a high 
diagram depicts, "High-High" cluster areas are in the upper regions of the YEB, and "Low-Low" cluster areas are mainly in the middle and lower regions. With evolution time, there are fewer provinces showing significant agglomeration, and the "Low-Low" cluster areas and "High-Low" outlier areas gradually disappear. This phenomenon shows that the overall coupling coordination degree of the YEB maintains an upward trend, and the difference and imbalance between regions have been reducing.

As a major strategic development region in China, the overall level of urbanization in the YEB has developed relatively fast in recent decades, while the development level of the atmospheric environment is relatively backward. This competing trend makes it necessary to increase investment in atmospheric environmental governance and enhance people's awareness of energy conservation and emission reduction. We recommend that the Chinese government designate the main towns (i.e., Shanghai, Wuhan and Chongqing) along the Yangtze River as the nodes and build a green development axis to encourage the gradient development of the economy from the coast to upstream and realize the coordinated development of the YEB. In view of the "spillover effect" among provinces, the local government could enhance the industrial interaction among regions and promote exchanges for air pollution prevention and control technologies, thereby providing complementary advantages to achieve a continuous optimization of the overall coupling coordination degree in the YEB.

This paper has important practical and application value for promoting new urbanization construction and improving the atmospheric environment in the YEB. Nevertheless, some issues remain to be further studied: 1) in the future, a variety of methods besides entropy method can be used to improve the process of index construction; 2) in addition to the provincial spatial scale, smaller scales, such as the prefecture level, should be considered for a more accurate analysis; 3) Except in addition to the rook adjacency matrix, distance or other space weight definition standards should be used to find an optimal one.

\section{Declarations}

\section{Author contributions}

Yuxia Deng wrote the paper, analyzed the data and made figures. Ting Huang conceptualized, analyzed the data and revised the paper.

Xianglian Wang and Ya Liu calculated the results. Lian Zeng and Xiangwen Zhang collected data. Daishe Wu organized resources. All the authors read and contributed to the submitted version of the manuscript.

\section{Funding}

This work was financially supported by the National Natural Science Foundation of China (41402312) and the Natural Science Foundation of Jiangxi Provincial (2018BAB213017).

\section{Data Availability}




\section{Conflict of interest}

The authors declare that they have no conflict of interest.

\section{Consent to participate}

All authors were participated in this work

\section{Consent to publish}

All authors agree to publish.

\section{References}

1. Anselin, L., 1995. Local Indicators of Spatial Association-LISA. Geographical Analysis 27(2), 93-115. https://doi.org/10.1111/j.1538-4632.1995.tb00338.x.

2. Anselin, L., 1996. Interactive Techniques and Exploratory Spatial Data Analysis. Regional Research Institute Working Papers.200. https://researchrepository.wvu.edu/rri_pubs/200.

3. Bai, L., Jiang, L., Yang, D.-y., Liu, Y.-b., 2019. Quantifying the spatial heterogeneity influences of natural and socioeconomic factors and their interactions on air pollution using the geographical detector method: A case study of the Yangtze River Economic Belt, China. J. Clean. Prod. 232, 692704. https://doi.org/10.1016/j.jclepro.2019.05.342.

4. Chen, J., Xu, C., Li, K., Song, M., 2018. A gravity model and exploratory spatial data analysis of prefecture-scale pollutant and CO2 emissions in China. Ecol. Indicators 90, 554-563. https://doi.org/10.1016/j.ecolind.2018.03.057.

5. Cheng, X., Long, R., Chen, H., Li, Q., 2019. Coupling coordination degree and spatial dynamic evolution of a regional green competitiveness system - A case study from China. Ecol. Indicators 104, 489-500. https://doi.org/10.1016/j.ecolind.2019.04.003.

6. Cliff,A.D.,Ord,J.K.,1981.Spatial and temporal analysis: Autocorrelation in space and time. Quantitative Geography: A British View;Pion:London,UK,127-144.

7. Cui, M., 2015. Coupling coordination relationship between urbanization and ecological environment in nine cities of Central Plains Urban Agglomeration. Econ. Geogr. 35(7), 72-78. https://doi.org/10.15957/j.cnki.jjdl.2015.07.011.

8. Dai, Y., Zhao, W., Li, J., 2018. Study on the coupling and coordination relationship between urbanization and ecological environment in Hunan Province. Yunnan Geographical Environment Research 30(05), 36-42. https://doi.org/CNKI:SUN:YNDL.0.2018-05-006.

9. Diao, X.D., Zeng, S.X., Tam, C.M., Tam, V.W.Y., 2009. EKC analysis for studying economic growth and environmental quality: a case study in China. J. Clean. Prod. 17(5), 541-548. https://doi.org/10.1016/j.jclepro.2008.09.007. 
10. Ding, L., Zhao, W., Huang, Y., Cheng, S., Liu, C., 2015. Research on the Coupling Coordination Relationship between Urbanization and the Air Environment: A Case Study of the Area of Wuhan. Atmos 6(10), 1539-1558. https://doi.org/10.3390/atmos6101539.

11. Dogan, E., Turkekul, B., 2016. CO2 emissions, real output, energy consumption, trade, urbanization and financial development: testing the EKC hypothesis for the USA. Environ Sci Pollut Res Int 23(2), 1203-1213. https://doi.org/10.1007/s11356-015-5323-8.

12. Getis, A., 2007. Reflections on spatial autocorrelation. Reg. Sci. Urban Econ. 37(4), 491-496. https://doi.org/10.1016/j.regsciurbeco.2007.04.005.

13. Grossman, G.M., Krueger, A.B., 1995. Economic Growth and the Environment*. The Quarterly Journal of Economics 110(2), 353-377. 10.2307/2118443.

14. Gupta,A.,2002.Geoindicators for tropical urbanization. Environ. Geol. 42(7), 736-742. https://doi.org/10.1007/s00254-002-0551-x.

15. Han, N., Yu, W., 2016. Spatial Characteristics and Influencing Factors of Industrial Waste Gas Emission in China. Scientia Geographica Sinica 36(02), 196-203. https://doi.org/10.13249/j.cnki.sgs.2016.02.005.

16. Han, X., Ma, C., 2013. A discussion on the improvement of entropy value weighting. Friends of Accounting(31), 18-20. https://doi.org/CNKI:SUN:KJZY.0.2013-31-007.

17. Jiang, B., Ding, L., Fang, X., 2019. Sustainable Development of New Urbanization from the Perspective of Coordination: A New Complex System of Urbanization-Technology Innovation and the Atmospheric Environment. Atmos 10(11), 652. https://doi.org/10.3390/atmos10110652.

18. Li, Y., Li, Y., Zhou, Y., Shi, Y., Zhu, X., 2012. Investigation of a coupling model of coordination between urbanization and the environment. J. Environ. Manage. 98, 127-133. https://doi.org/10.1016/j.jenvman.2011.12.025.

19. Liang, L., Wang, Z., Fang, C., Sun, Z., 2019. Spatial-temporal differentiation and synergistic development pattern of urbanization and eco-environment in Beijing-Tianjin-Hebei urban agglomeration. Acta Ecol. Sin./Shengtai Xuebao 39(4), 1212-1225. https://doi.org/CNKI:SUN:STXB.0.2019-04-009.

20. Liao, C., 1999. Quantitative judgement and classification system for coordinated development of environment and economy-A case study of the city group in the Pearl River Delta. Trop. Geogr./Redai Dili(02), 76-82. https://doi.org/10.13284/j.cnki.rddl.000443.

21. Liao, S., Wu, Y., Wong, S.W., Shen, L., 2020. Provincial perspective analysis on the coordination between urbanization growth and resource environment carrying capacity (RECC) in China. Sci. Total Environ. 730, 138964. https://doi.org/10.1016/j.scitotenv.2020.138964.

22. Lin, B., Zhu, J., 2018. Changes in urban air quality during urbanization in China. J. Clean. Prod. 188, 312-321. https://doi.org/10.1016/j.jclepro.2018.03.293.

23. Liu, N., Liu, C., Xia, Y., Da, B., 2018. Examining the coordination between urbanization and ecoenvironment using coupling and spatial analyses: A case study in China. Ecol. Indicators 93, 1163- 
24. Liu, W., Jiao, F., Ren, L., Xu, X., Wang, J., Wang, X., 2018. Coupling coordination relationship between urbanization and atmospheric environment security in Jinan City. J. Clean. Prod. 204, 1-11. https://doi.org/10.1016/j.jclepro.2018.08.244.

25. Meng, B., Wang, J., Andrew, R., Xiao, H., Xue, J., Peters, G.P., 2017. Spatial spillover effects in determining China's regional CO2 emissions growth: 2007-2010. Energy Econ. 63, 161-173. https://doi.org/10.1016/j.eneco.2017.02.001.

26. Northam,R.M.,1975.Urban Geography.John Wiley \& Sons,New York,NY.

27. Rapport, D., Friend, A. (1979). Towards a Comprehensive Framework for Environmental Statistics: A Stress-Response Approach. Statistics Canada 11-510, Ottawa.

28. Tang, Z., 2015. An integrated approach to evaluating the coupling coordination between tourism and the environment. Tourism Management 46, 11-19. https://doi.org/10.1016/j.tourman.2014.06.001.

29. Ulucak, R., Bilgili, F., 2018. A reinvestigation of EKC model by ecological footprint measurement for high,middle and low income countries.J.Clean.Prod.188,144-157. https://doi.org/10.1016/j.jclepro.2018.03.191.

30. Wang, Q., Yuan, X., Ma, C., Zhang, Z., Zuo, J., 2012. Research on the impact assessment of urbanization on air environment with urban environmental entropy model: a case study. Stochastic Environmental Research and Risk Assessment 26(3), 443-450. https://doi.org/10.1007/s00477-0110493-5.

31. Wang, Q., Yuan, X., Zhang, J., Mu, R., Yang, H., Ma, C., 2013. Key evaluation framework for the impacts of urbanization on air environmentf-A case study. Ecol. Indicators 24, 266-272. https://doi.org/10.1016/j.ecolind.2012.07.004.

32. Wang,S.,Fang,C.,Wang,Y.,Huang,Y.,Ma,H.,2015.Quantifying the relationship between urban development intensity and carbon dioxide emissions using a panel data analysis. Ecol. Indicators 49,121-131. https://doi.org/10.1016/j.ecolind.2014.10.004

33. Wang, S., Ma, H., Zhao, Y., 2014. Exploring the relationship between urbanization and the ecoenvironment-A case study of Beijing-Tianjin-Hebei region. Ecol. Indicators 45, 171-183. https://doi.org/10.1016/j.ecolind.2014.04.006.

34. Xing, L., Xue, M., Hu, M., 2019. Dynamic simulation and assessment of the coupling coordination degree of the economy-resource-environment system: Case of Wuhan City in China. J. Environ. Manage. 230, 474-487. https://doi.org/10.1016/j.jenvman.2018.09.065.

35. Xu, D., Hou, G., 2019. The Spatiotemporal Coupling Characteristics of Regional Urbanization and Its Influencing Factors: Taking the Yangtze River Delta as an Example. Sustainability 11(3). https://doi.org/10.3390/su11030822.

36. Yuan, X., Ren, L., Mu, R., Ma, C., Zhang, K., 2010. Eco-industry and sustainability for the coal industry - a case study from YZCMG, China. International Journal of Sustainable Development \& World Ecology 17(2), 149-156. https://doi.org/10.1080/13504501003603215.

37. Zhang, J., Li, J., Wang, X., 2020. Exploring the Dynamics of Carbon Emission in China via SpatialLoading [MathJax]/jax/output/CommonHTML/fonts/TeX/fontdata.js nthesis: Computational Social Science and 
Humanities. Springer International Publishing, Cham, pp. 181-198. https://doi.org/10.1007/978-3030-52734-1_13

38. Zhang, P., Su, F., Li, H., Sang, Q., 2008. Coordination Degree of Urban Population, Economy, Space, and Environment in Shenyang Since 1990. Chinese Journal of Population,Resources and Environment 18(2), 115-119. https://doi.org/10.1016/S1872-583X(09)60004-8.

39. Zhang, Y., Liu, H., 2017. Spatio-temporal analysis of coupling coordination between urbanization and ecological environment in the Yangtze River Economic Belt. Bulletin of Soil and Water Conservation 37(6), 334-340. https://doi.org/10.13961/j.cnki.stbctb.2017.06.054.

40. Zou, Z.-h., Yun, Y., Sun, J.-n., 2006. Entropy method for determination of weight of evaluating indicators in fuzzy synthetic evaluation for water quality assessment. JEnvS 18(5),1020-1023. https://doi.org/10.1016/S1001-0742(06)60032-6.

\section{Figures}

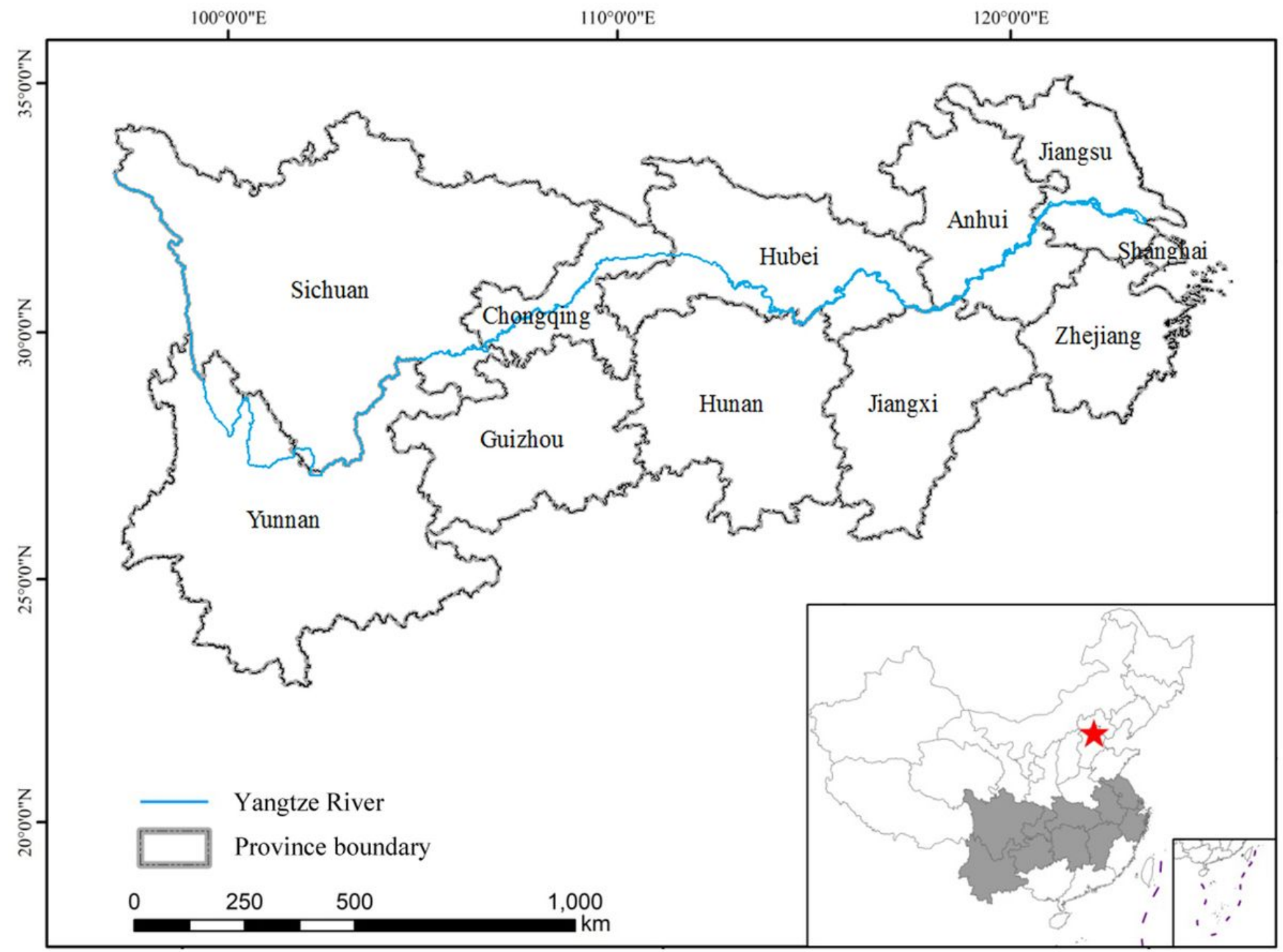


Study area.

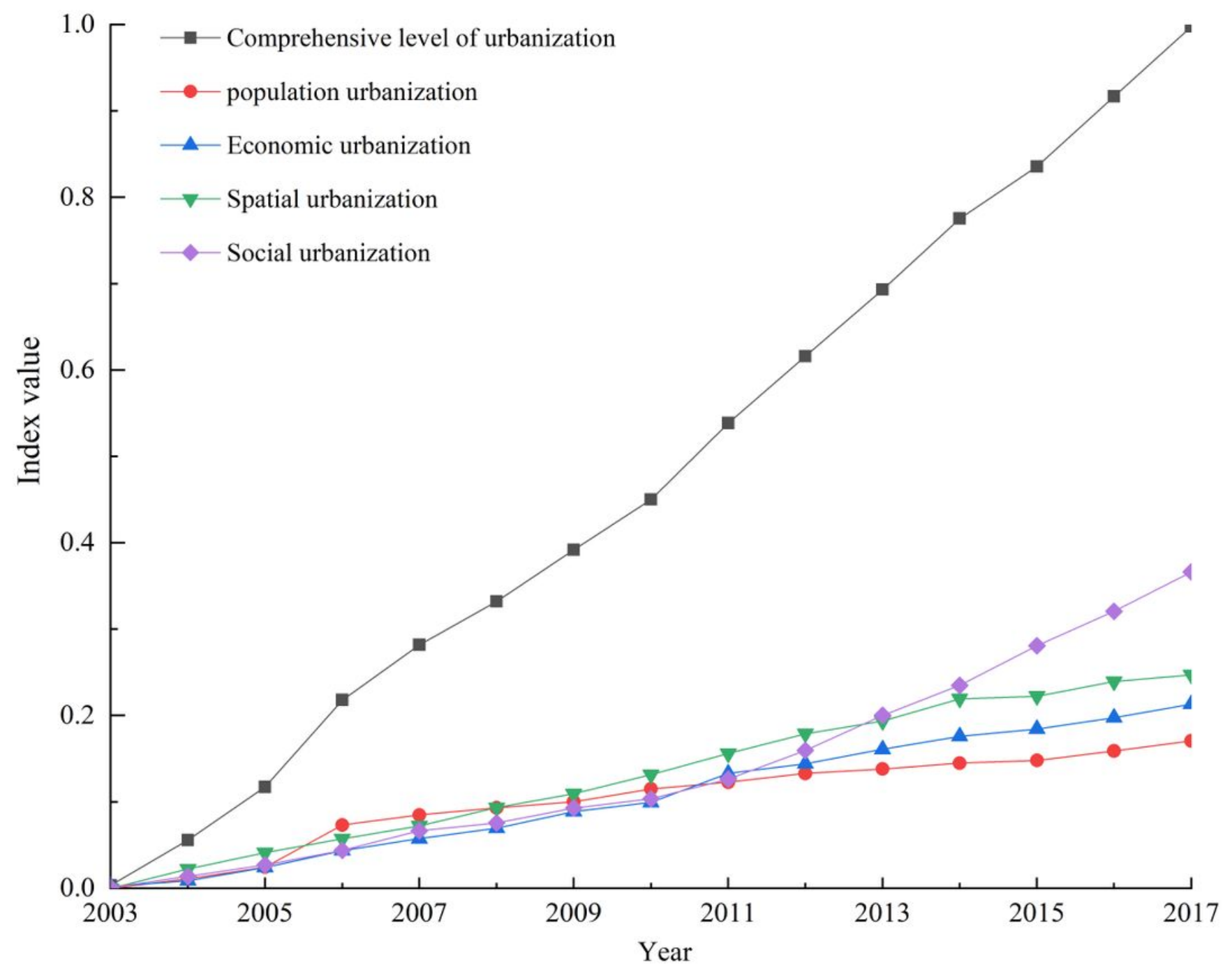

\section{Figure 2}

The trend of the comprehensive level in the urbanization system. 


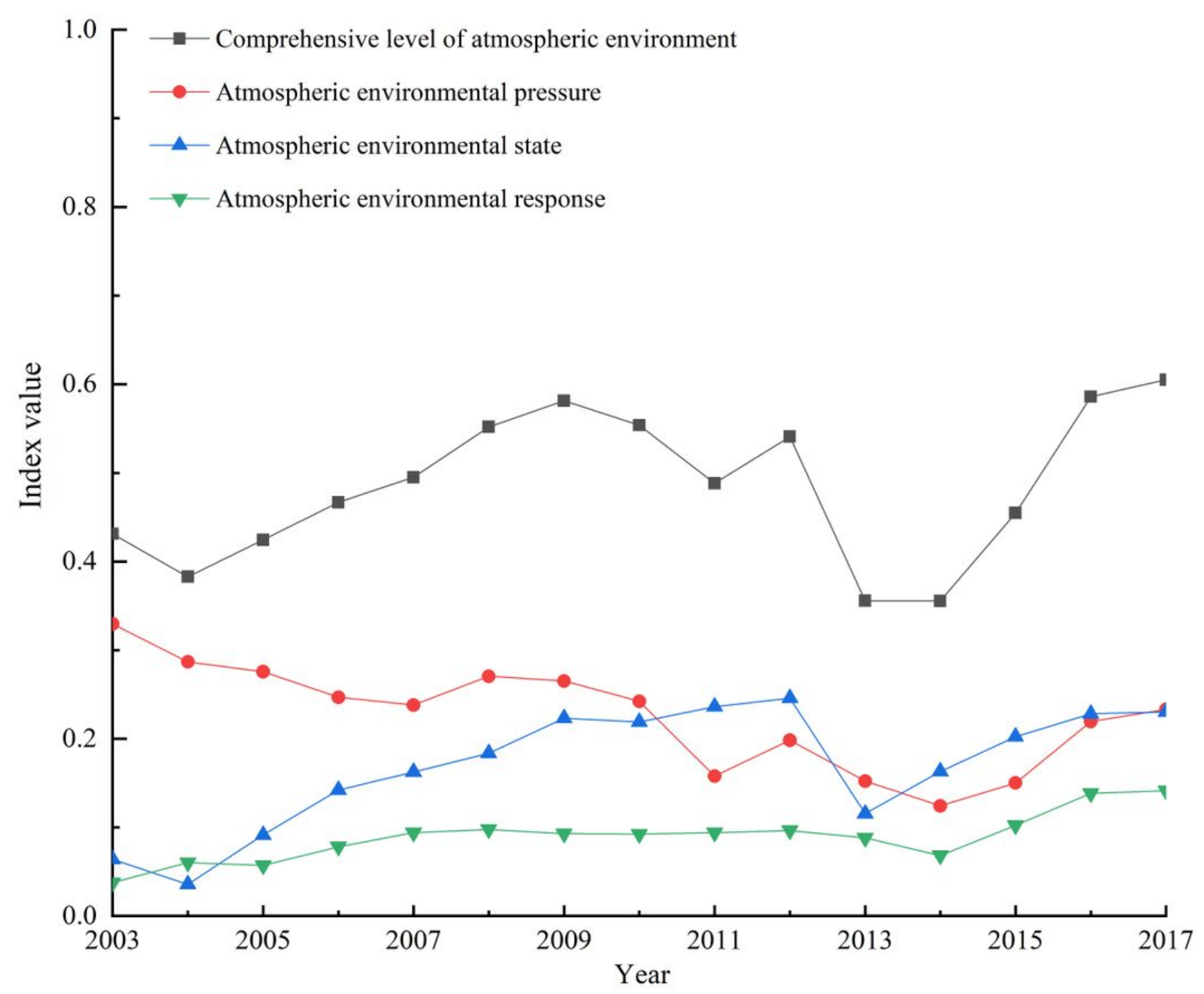

\section{Figure 3}

The trend of the comprehensive level in the atmospheric environment system. 


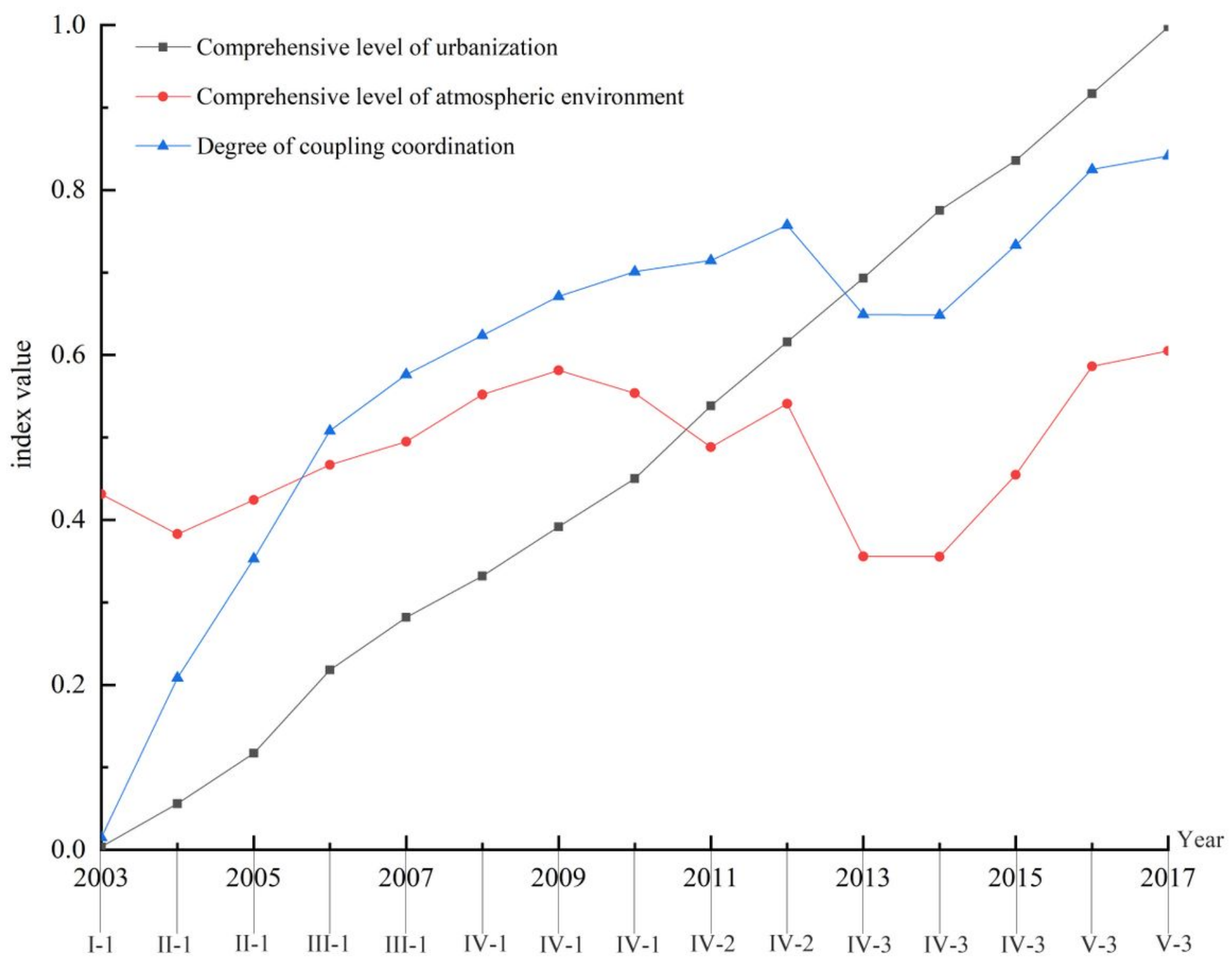

Figure 4

Coupling coordination degree evolution curve of urbanization and atmospheric environment. 

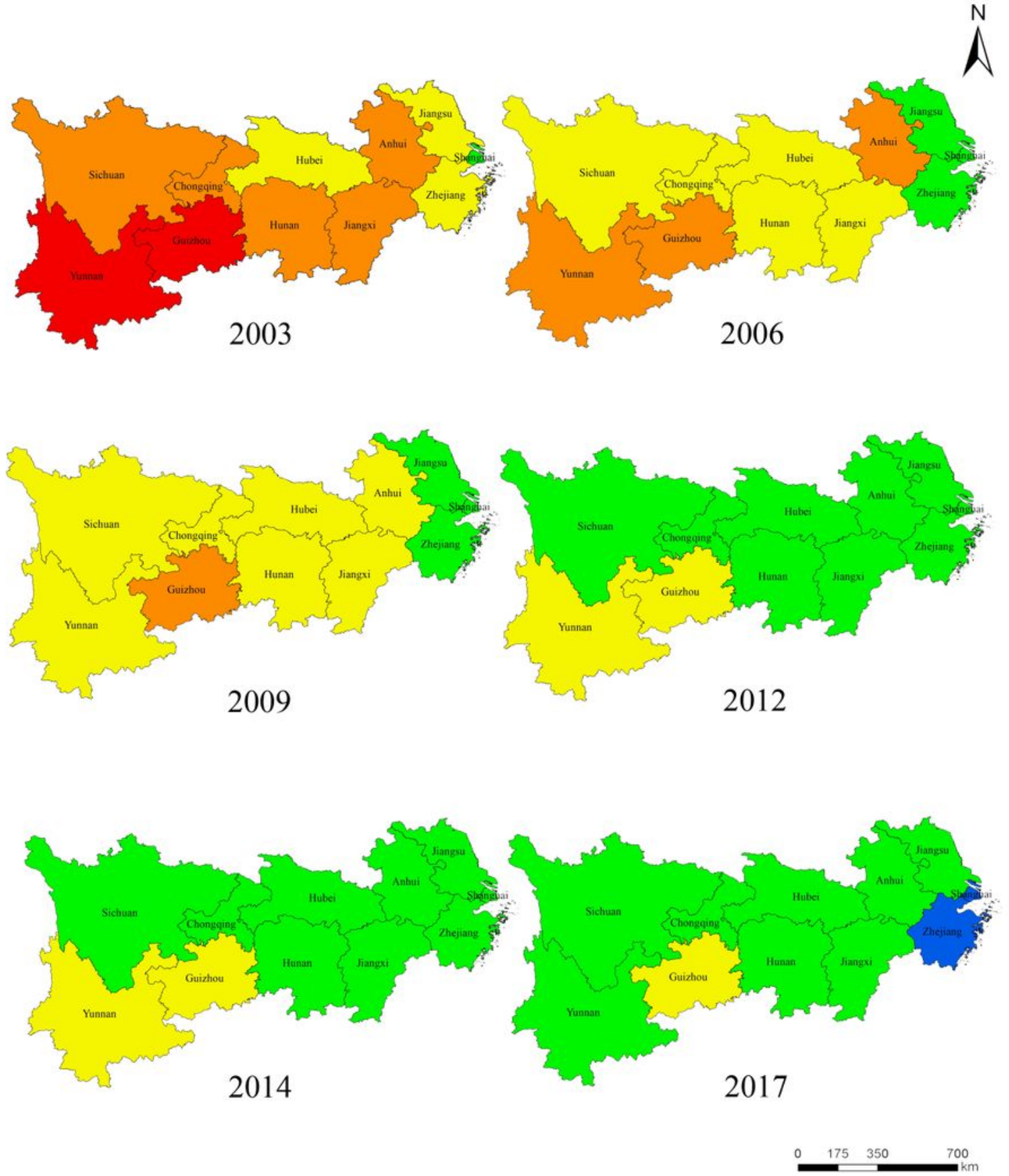

Coupling coordinated develoment types

Seriously uncoordinated

Moderately uncoordinated

Barely coordinated

Moderately coordinated

Superiorly coordinated

\section{Figure 5}

Types of coupling coordinated development between urbanization and atmospheric environment. 


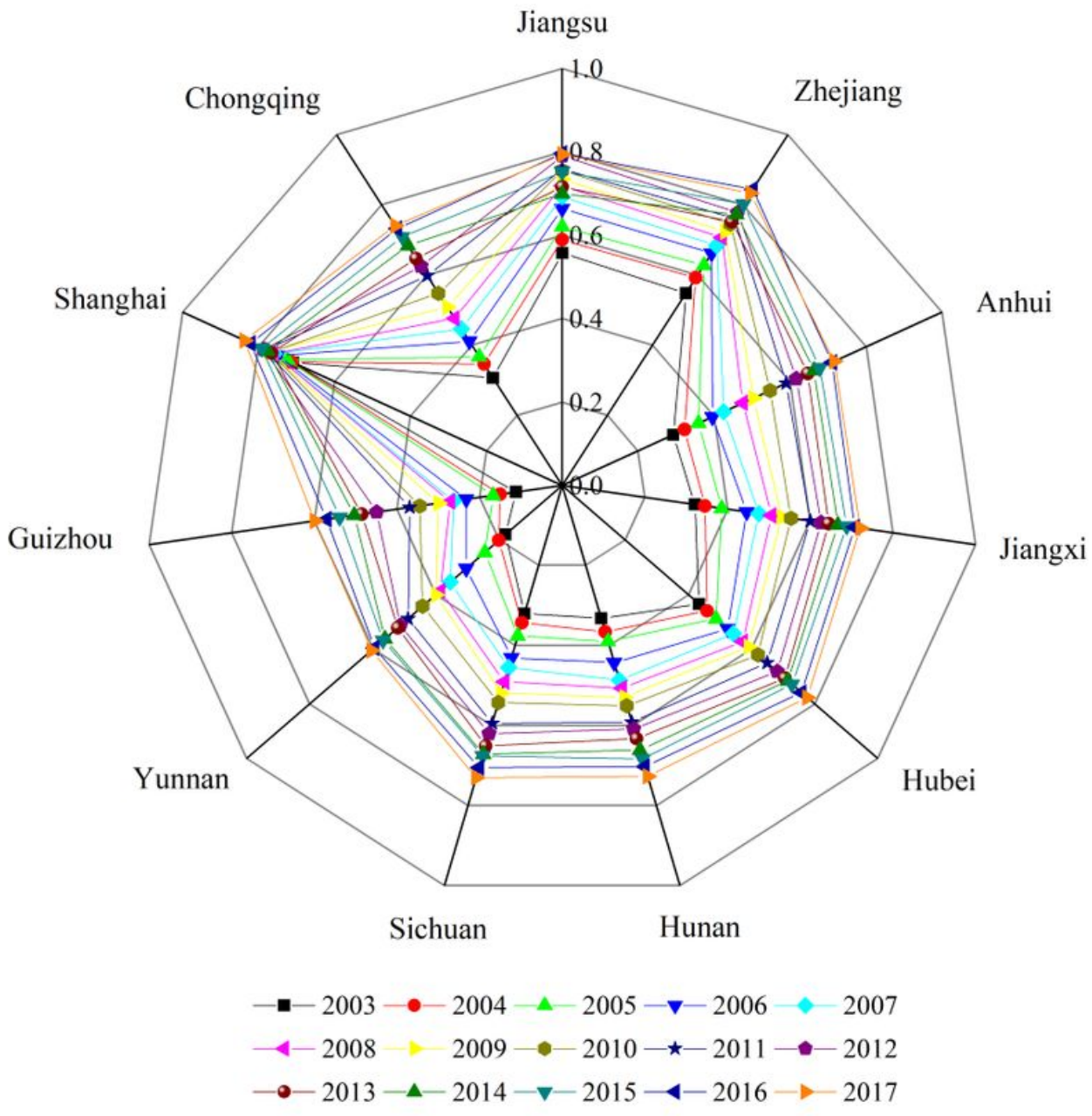

Figure 6

Radar map of coupling coordination degree in the Yangtze River Economic Belt. 

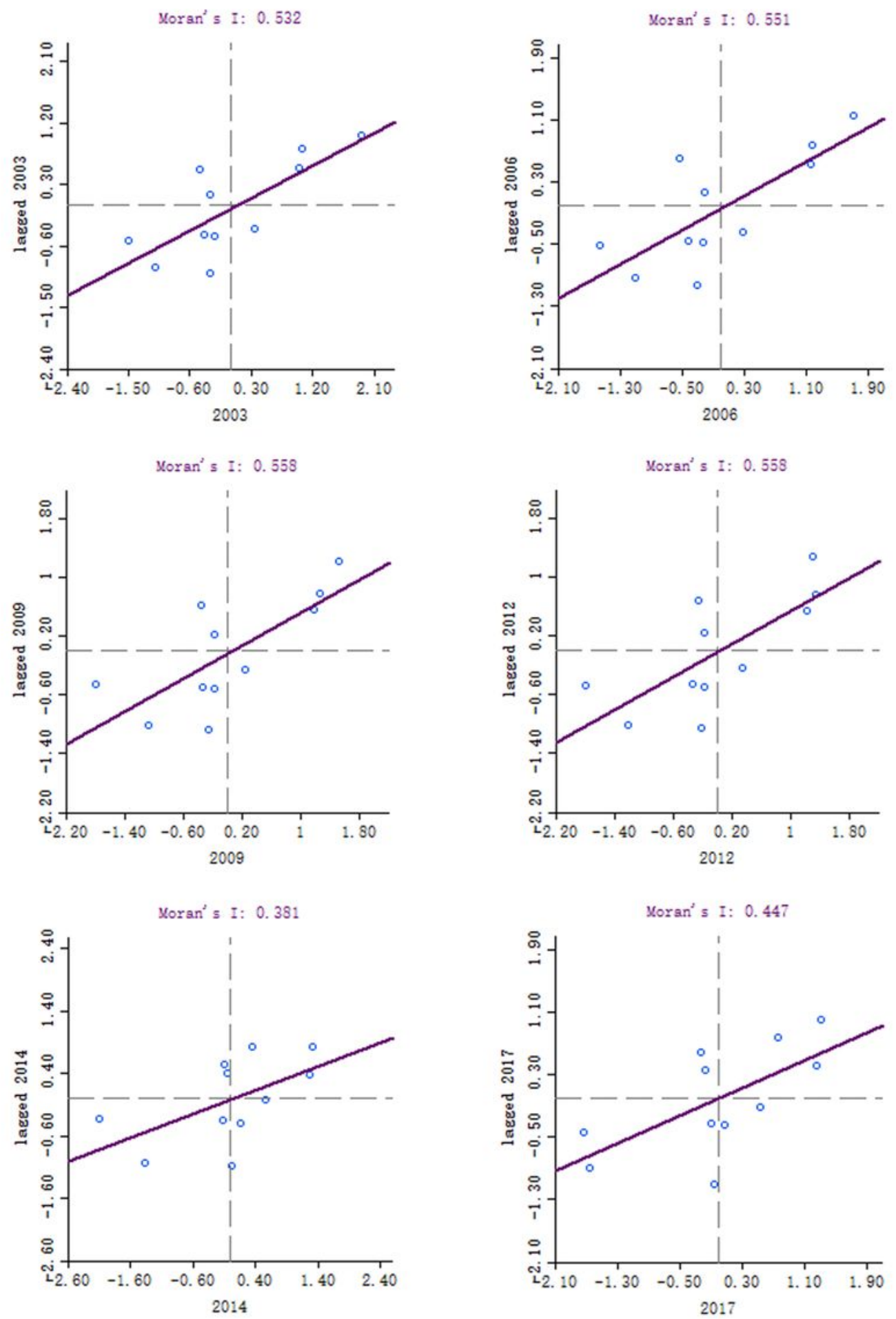

Figure 7

Moran scatter plot of coupling coordination. 

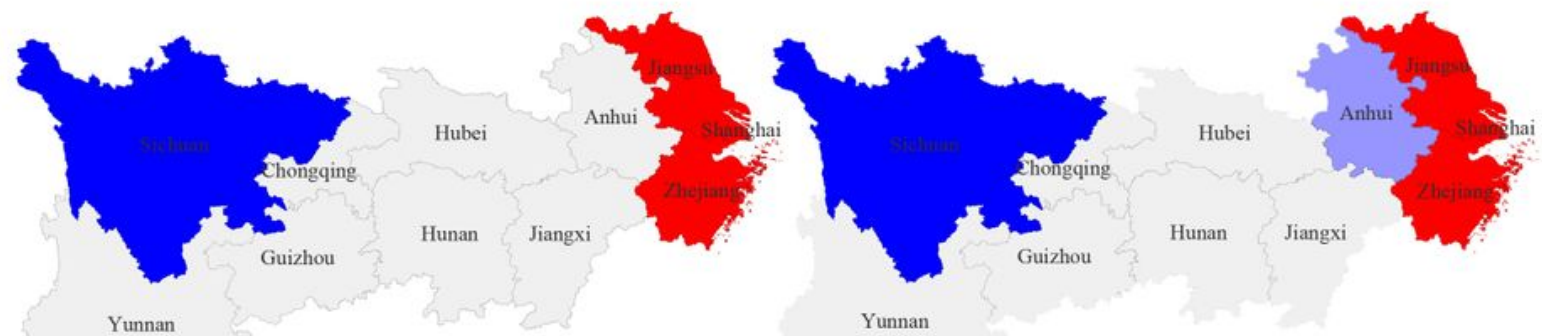

2003

Not significant

High-High Cluster

Low-Low Cluster

Low-High Outlier

High-Low Outlier

Yunnan

2006

Not significant

High-High Cluster

Low-Low Cluster

Low-High Outlier

High-Low Outlier

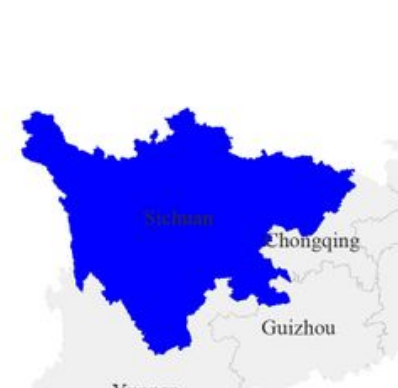

Yunnan
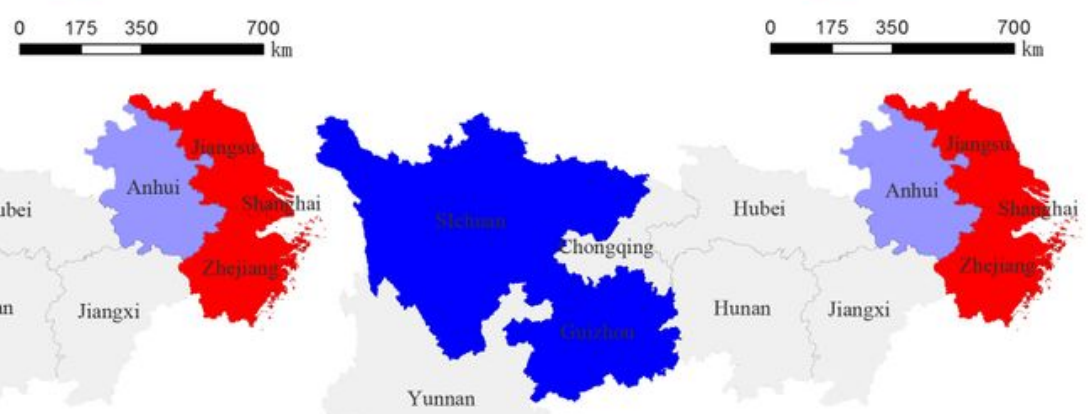

2009

Not significant

High-High Cluster

Low-Low Cluster

Low-High Outlier

High-Low Outlier

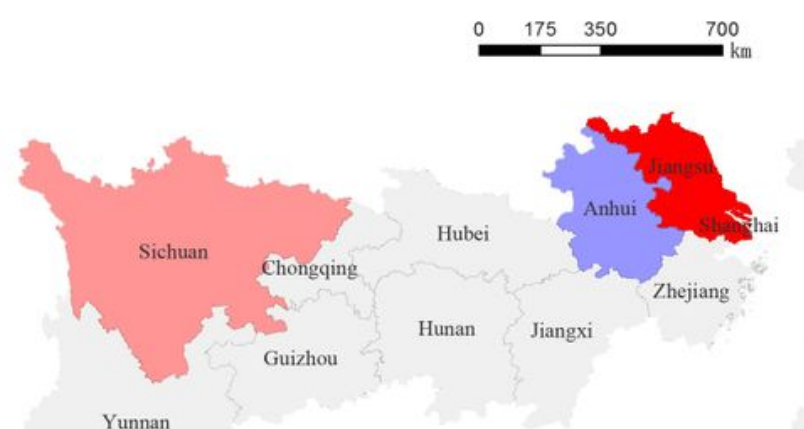

2014

Not significant

High-High Cluster

Low-Low Cluster

Low-High Outlier

High-Low Outlier

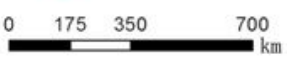

Yunnan

\section{2}
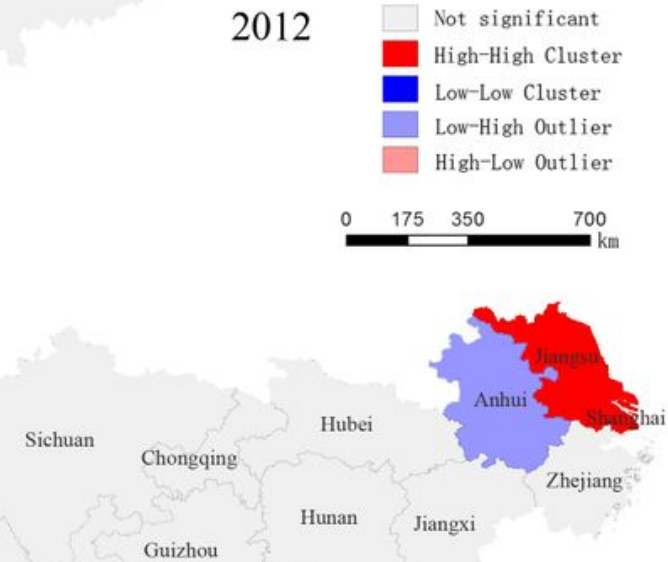

Yunnan

Guizhou

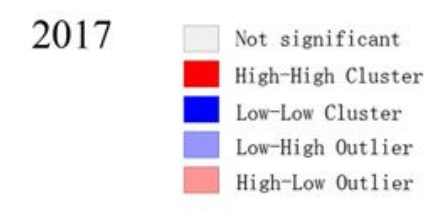

$\begin{array}{llll}0 & 175 \quad 350 \quad 700 \\ \end{array}$

\section{Figure 8}

LISA diagram of coupling coordination degree. 